\title{
Ética y humanismo en la educación
}
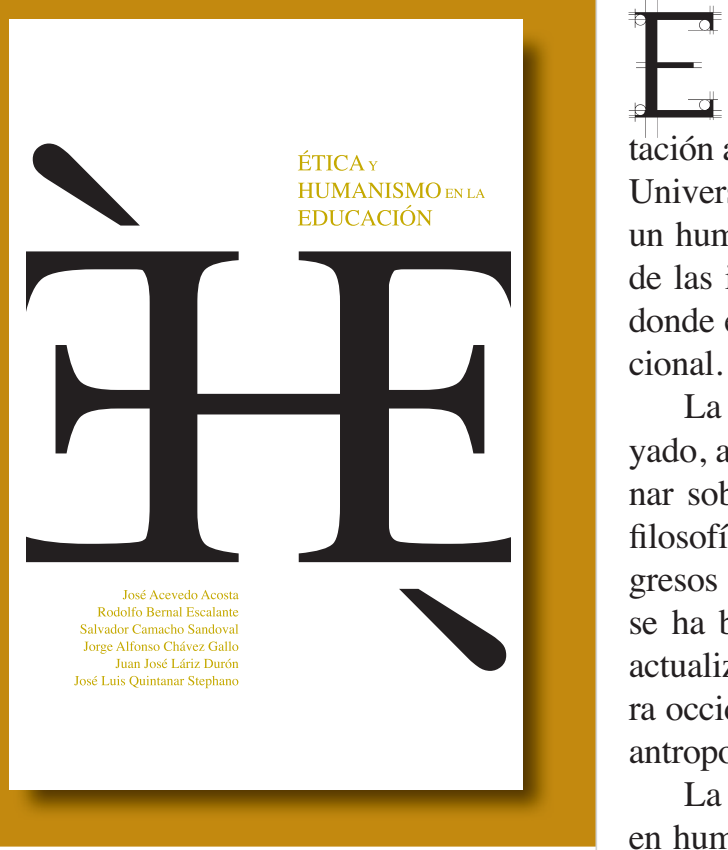

1 texto Ética y humanismo en la educación es una invitación a dialogar, con algunos profesores e investigadores de la Universidad Autónoma de Aguascalientes, sobre la visión de un humanismo actual, que responda a las necesidades y retos de las instituciones educativas, principalmente de aquellas en donde el humanismo es parte de su Modelo Educativo Institucional.

La comunidad académica en nuestra universidad ha ensayado, a través de su historia, distintas dinámicas para reflexionar sobre el proyecto humanista que define en el Ideario su filosofía institucional: organizando debates, exposiciones, congresos y cursos, entre otras modalidades. En esos proyectos, se ha buscado revisar las distintas formas de construcción y actualización de una filosofía iniciada, oficialmente en la cultura occidental, con el Renacimiento como una filosofía cultural antropológica en oposición a la concepción teocéntrica.

La filosofía humanista es un ensayo del ser que desemboca en humanidad, un ejercicio libre del pensamiento, a través de las experiencias y del tiempo para construir la dignidad de la vida cotidiana, por medio del reconocimiento de los excluidos, históricamente, en sus derechos de libertad e igualdad política. Los autores del honesto libro que presento, reconstruyen, desde su experiencia y sus preocupaciones, el sentido del humanismo en las relaciones y en la mediación de los valores con los otros. Como filosofía, el humanismo es una concepción ética compleja y trágica, compleja porque, como menciona Edgar Morin, "es de naturaleza dialógica y debe afrontar a menudo la ambigüedad y la contradicción" (2006) y es trágica porque sus problemas no tienen soluciones definitivas.

La invitación de los autores se dirige a revisar nuestra visión del humanismo desde su relación con los estudiantes y sus profesiones, con el ejercicio de la autoridad institucional y con los proyectos de modernización educativa y, finalmente, con el uso de los sistemas tecnológicos y el desarrollo de la investigación científica. Es, en el diálogo con los autores del texto, que se actualiza y revitaliza el sentido del humanismo universitario, aprovechando con ello, además, la oportunidad de clarificar la 
historia de las ideas que le han ido dando cuerpo al paradigma del humanismo.

En una sociedad en donde la publicidad y los medios fomentan y promueven el consumismo y el hedonismo, se hace imperativa una reflexión sobre el sentido ético de la vida individual y humana, más allá de los síntomas propios de la época, como podría ser la indiferencia o los, cada vez más frecuentes, trastornos obsesivo compulsivos de acumulación, que son patologías de una exitosa economía de mercado que promueve la codicia como principio: "tengo, luego existo".

En esta invitación es muy interesante descubrir la propuesta de cada escritor, según el enfoque de su preocupación por el humanismo universitario. Por ejemplo, el maestro Rodolfo Bernal presenta una estrategia didáctica, contra la monstruosidad, buscando educar el espíritu humano e instruir la voluntad y la inteligencia de los alumnos, para recrear el desarrollo de la sensibilidad estética y la formación integral.

El maestro Alfonso Chávez, desde una crítica visión nietzscheana, cuestiona el reducir la visión universitaria a la formación profesional, pues los jóvenes tienen en la conquista de su libertad múltiples horizontes para diversificar su ser y sus talentos, a través de las obras personales y culturales.

¿Cómo comprender un posible humanismo postmoderno? Es una de las interrogantes que sirven de reflexión al maestro Juan José Láriz en su revisión de la educación y de sus pilares, para construir en nuestro imaginario cultural la sociedad educada. ¿Cuáles son los compromisos de las ciencias y las instituciones universitarias modernas en la configuración de personas plenas y equilibradas que plasmen los valores éticos en sus actitudes cotidianas y en su formación profesional? Es ésta la pregunta sobre la que reflexionan los investigadores José Luis Quintanar, Salvador Camacho y José Acevedo, quienes de manera crítica y experimentada cuestionan las tendencias modernistas y empresariales que van entorpeciendo y extraviando el sentido universal de lo humano, al carecer este rubro vital de evaluación en las certificaciones del ISO 9001.

Con esta obra, podemos aprovechar la oportunidad de integrarnos al diálogo sobre el humanismo, interpelando a los profesores que exponen su pensamiento y con quienes podemos debatir algunas ideas, siguiendo el espíritu universitario, además de adquirirlo en nuestra librería universitaria para disfrutar de su sabia compañía.

Fuentes de consulta

Camps, V. (2001). Una vida de calidad. España: Editorial Ares y mares.

Morin, E. (2006). El método 6: Ética. España: Cátedra.

Levinas, E. (1998). Humanismo del otro hombre. España: Caparrós editores. 